\title{
Todas as ciências são sociais
}

As sociedades contemporâneas vivenciam um acúmulo inédito de desafios políticos, sociais e de saúde pública. Questões históricas nunca superadas mesclam-se a questões conjunturais, agudizando as desigualdades, os preconceitos, o sofrimento e as mortes evitáveis. Em meio a uma pandemia global, em que a compreensão do processo saúde-doença é multidimensional, várias abordagens são necessárias para compreender a história natural da doença, bem como sua repercussão nos aspectos social, econômico, político e cultural. Apesar das tendências negacionistas, a pandemia revelou a centralidade da ciência para a solução dessa crise ${ }^{1}$. Evidenciou também a importância de organizações nacionais e internacionais de saúde pública para seu enfrentamento. É necessário que a sociedade civil compreenda a importância de investimentos em pesquisas, tecnologia e inovação para o desenvolvimento dos países.

A despeito dessa conjuntura pouco favorável, ou talvez graças a ela, assistimos a mudanças importantes no método de trabalho nas ciências. As pesquisas se tornaram mais abertas à interdisciplinaridade, concebendo novas formas de relacionamento com a sociedade civil e indagando sobre as implicações éticas de um saber hermético que normalmente a academia produz. Com a crise pandêmica, os métodos científicos se adaptaram às exigências dos interlocutores; a postura dos pesquisadores tornou-se mais engajada, e as colaborações se mostraram cada vez mais necessárias, em distintos campos, unificados sobre a premissa de que todas as ciências são sociais. A permanente renovação científica abrange a própria reflexão sobre a construção dos fatos. Por isso, a atividade científica é, ao mesmo tempo, um posicionamento de vigilância epistemológica e de crítica social. Há em curso uma reafirmação de preconceitos e cegueiras que embasam posturas neoconservadoras de desprezo ao conhecimento científico ${ }^{2}$. A desconstrução dessa agenda anticiência é urgente.

A chamada pública que deu origem a este número recebeu manuscritos que contribuíssem em temas previamente elaborados. Estes temas incluem aspectos relacionados a racismos e seus impactos na saúde, com artigos que analisam a discriminação racial entre mulheres em processos de abortamento provocado e estudo com idosos quilombolas; e pautas identitárias, com discussão sobre masculinidades e sofrimento mental. Alguns temas associados aos Objetivos do Desenvolvimento Sustentável e a Agenda 2030 surgem em estudos sobre sistemas alimentares e mortalidade materna. A Atenção Primária à Saúde e seus fundamentos estão incluídos no escopo deste número, com artigos que abordam o território como espaço de construção e avaliação da atenção primária. A governança global é tema presente, com estudos que realizam análises de políticas nacionais de saúde dos adolescentes, controle de câncer e de alimentação saudável; bem como de sistemas de saúde comparados.

A demografia possui interseção importante com a saúde pública: o número apresenta estudos que caracterizam a mortalidade em 30 anos de SUS, que associam o padrão de transição demográfica a indicadores sociais e analisam os ciclos de desastres naturais e o impacto entre idosos. Nesta esteira, para além das doenças infecciosas ou condições crônicas, há a violência tipificando a tripla carga de doenças. Trata-se de uma marcada característica da América Latina, e ela é explorada por artigos sobre narrativas policiais sobre juventudes de periferia e insegurança pública. Finalmente, há artigos que abordam a pandemia por COVID-19, com análises desde a avaliação de classes sociais à disseminação espacial e temporal do Sars$\mathrm{CoV}-2$, além de uma reflexão sobre o negacionismo e a capacidade institucional de resposta à pandemia.

A Escola Nacional de Saúde Pública Sergio Arouca é uma escola pioneira no ensino e pesquisa em saúde pública no Brasil. Procurando manter seu compromisso social e a defesa à ciência, o Programa de Pós-Graduação em Saúde Pública os convida a visitar o conteúdo deste número.

Boa leitura!

Fátima Regina Cecchetto (https://orcid.org/0000-0003-3080-5582) ${ }^{1}$

Marcelo Rasga Moreira (https://orcid.org/0000-0003-3356-7153) ${ }^{2}$

Raphael Mendonça Guimarães (https://orcid.org/0000-0003-1225-6719) ${ }^{2}$

${ }^{1}$ Laboratório de Educação em Ambiente e Saúde, Instituto Oswaldo Cruz, Fundação Oswaldo Cruz. Rio de Janeiro RJ Brasil.

${ }^{2}$ Departamento de Ciências Sociais, Escola Nacional de Saúde Pública Sergio Arouca, Fundação Oswaldo Cruz. Rio de Janeiro RJ Brasil.

\section{Referências}

1. Caponi S. Covid-19 no Brasil: entre o negacionismo e a razão neoliberal. Estudos Avançados 2020; 34(99):209-224.

2. Thorp HH. Do us a favor. Science 2020; 367:1169. 